\title{
Performance Analysis of Direct Power Controlled PWM Rectifier under Disturbed AC Line Voltage
}

\author{
H.Azizi and A.Vahedi \\ Power Engineering Department-Iran University of Science \&Technology \\ avahedi@iust.ac.ir_Hosseinazizi57@yahoo.com
}

\begin{abstract}
Voltage and current source inverter are widely used in electrical motor drives. In this drives, DC voltage (or current) are usually provided from phase control or line commutation rectifiers. Because of disadvantage \& limitation of this converter, some new topologies are presented in advanced drive such as PWM rectifier. Thanks to well known capabilities of PWM rectifier, classical converter's problem can be overcome. There are several PWM rectifier control strategies. In this paper these control methods are introduced. At first, performance of the Direct Power Control (DPC) PWM rectifier is studied under balanced voltage condition. As line voltage disturbance are often considerable in industrial applications, rectifier performance under disturbed line voltage is investigated. For this purpose a DPC method is implemented in MATLAB/SIMULINK environment. Based on simulation results, DPC-PWM rectifier performances under unbalance and voltage sag is discussed.
\end{abstract}

\section{Keywords:}

Direct power control, voltage oriented control, PWM rectifier, space vector modulation

\section{Introduction}

Today voltage and current source inverter are widely used in electrical motor drives. In this drives, DC voltage or current are usually obtained by using rectifiers with phase control and line commutation converter. This type of rectifiers is the most used method in industrial applications. The most important disadvantages of classical rectifiers are: low order current harmonics generation on the $\mathrm{AC}$ line, lagging displacement factor establishment to the utility grid that in its turn consume an important amount of reactive power, unidirectional power transmission and large DC link filter [1,2,3]. Besides, new limit has been applied by standards such as IEEE5191992 and IEC 61000-3-2/IEC 6100-3-4 that indicate the current harmonic limits of power electronic converters $[4,5,6]$.To overcome these problems in past few years PWM rectifiers are presented. Thanks to well known capabilities such as power regeneration, low harmonic input current, sinusoidal input current wave form, high total power factor, controlled dc-link voltage, small filter, 4-quadrant operation (bidirectional power transmission), PWM rectifiers become more and more popular in industry application $[3,4]$. There are several control strategies to control PWM rectifier such as Voltage oriented control (VOC) in which an internal current loop guarantees the high dynamics operation $[7,8,9]$. This method largely depends on the quality of the applied current control strategy. Another control strategy is direct power control
(DPC) that is based on the instantaneous active \& reactive power control loops and there is no need to PWM modulator block. because the converter switching state are appropriately selected by a switching table based on the instantaneous errors between the command and estimated values of active and reactive power, therefore the key point for implementation of DPC strategies is a correct and fast estimation of the active and reactive line power[5]. In DPC method, the error of estimated instantaneous active and reactive power is influenced by switching state and total line impedance (AC side inductance and motor cable inductance for long cable) other new methods of PWM rectifier control are virtual flux direct power control (VF-DPC) and virtual flux voltage oriented (VF-VOC) method. Each of previous methods has some practical advantages and disadvantages. In this paper first the mentioned control methods are introduced, then the direct power control PWM rectifier (DPC) based on the space vector modulation is discussed. First performance of the Direct Power Control is studied under balanced voltage condition. As line voltage disturbance has a undesirable effect on industrial speed control drive, it is important to study the performance of these converter in disturbed voltage condition. For this purpose a DPC method is implemented in MATLAB/SIMULINK environment. Based on simulation result DPC-PWM rectifier performance under unbalance and symmetrical voltage sag is discussed.

\section{The $P W M$ rectifier structure}

Structure of PWM rectifier is shown in fig.1. Electrical equations are drawn based on single phase equivalent circuit that is shown in fig.2. In this circuit $R, L$ represent the line inductor, $\underline{U}_{S}$, the line voltage and , $\underline{U}_{L}$, the bridge converter voltage controllable from the DC-side depends on the modulation index and DC voltage level $[1,2,3]$.

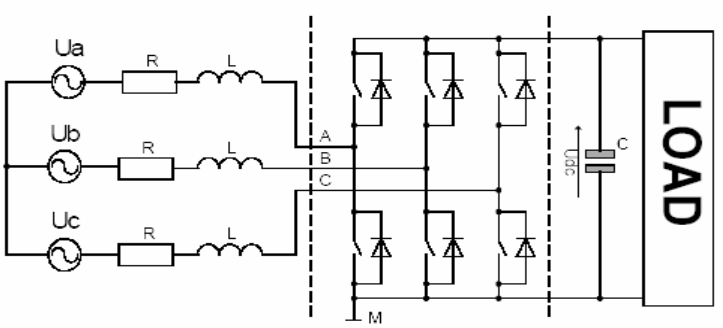

Fig.1. Structure of PWM-rectifier 


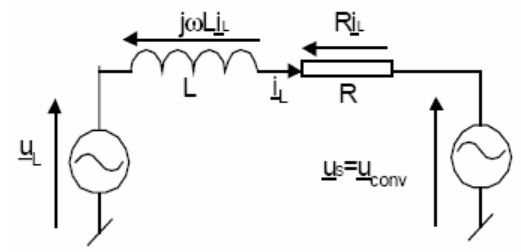

Fig.2. Single-phase equivalent circuit of the PWM rectifier

The voltage equation for this single phase circuit can be written as:

$$
\left[\begin{array}{c}
U_{a} \\
U_{b} \\
U_{c}
\end{array}\right]=R\left[\begin{array}{l}
i_{a} \\
i_{b} \\
i_{c}
\end{array}\right]+L \frac{d}{d t}\left[\begin{array}{l}
i_{a} \\
i_{b} \\
i_{c}
\end{array}\right]+\left[\begin{array}{l}
U_{s a} \\
U_{s b} \\
U_{s c}
\end{array}\right]
$$

For the balanced three-phase voltage PWM rectifier equations in stationary reference can be written as:

$$
\begin{aligned}
& U_{L}=\left[\begin{array}{ll}
U_{L \alpha} \\
U_{L \beta}
\end{array}\right]=\sqrt{\frac{2}{3}}\left[\begin{array}{cc}
1 & 1 / 2 \\
0 & \sqrt{\frac{3}{2}}
\end{array}\right]\left[\begin{array}{l}
U_{a b} \\
U_{b c}
\end{array}\right] \\
& i_{L}=\left[\begin{array}{l}
i_{L \alpha} \\
i_{L \alpha}
\end{array}\right]=\sqrt{\frac{2}{3}}\left[\begin{array}{cc}
\frac{3}{2} & 0 \\
\frac{\sqrt{3}}{2} & \sqrt{3}
\end{array}\right]\left[\begin{array}{l}
i_{a} \\
i_{b}
\end{array}\right]
\end{aligned}
$$

Also we can write PWM rectifier equation in synchronous rotating reference $(\mathrm{R}$ is neglected):

$$
\left[\begin{array}{l}
U_{L d} \\
U_{L q}
\end{array}\right]=L \frac{d}{d t}\left[\begin{array}{l}
i_{L d} \\
i_{L q}
\end{array}\right]+\omega\left[\begin{array}{c}
-i_{L q} \\
i_{L d}
\end{array}\right]+\left[\begin{array}{l}
U_{s d} \\
U_{s q}
\end{array}\right]
$$

voltage drop on line inductance, in vector form can be obtained from equations 4 as below::

$L \frac{d_{\underline{i}_{L d q}}}{d t}=\underline{u}_{L_{d q}}-j \omega L \underline{i}_{L d q}-\underline{u}_{s d q}$

in fig. 3 line voltage and current, as well as rectifier voltage of PWM rectifier are shown.

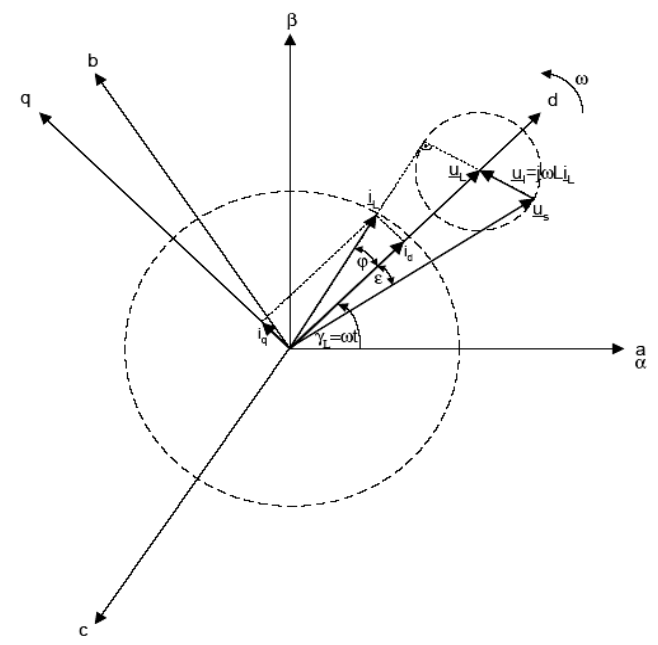

Fig.3. Relationship between the six active vectors and current vector movement

\section{PWM rectifier control methods}

PWM rectifier control strategies can be studied based on the voltage and current diagram shown in fig.3. In these methods the vector of the line current is controlled by controlling the voltage drop on the line inductance. Control methods of the PWM rectifier basically can be divided in two groups: voltage estimation based and virtual flux estimation based methods. Voltage oriented control (VOC) and direct power control (DPC) are voltage based methods. Fig.4 shows the Voltage oriented control (VOC) system Block scheme. As shown in figures, the internal current control loops guarantees high dynamics and static performance of rectifier. The performance of this control method is influenced by the current loop design $[7,8,9]$.

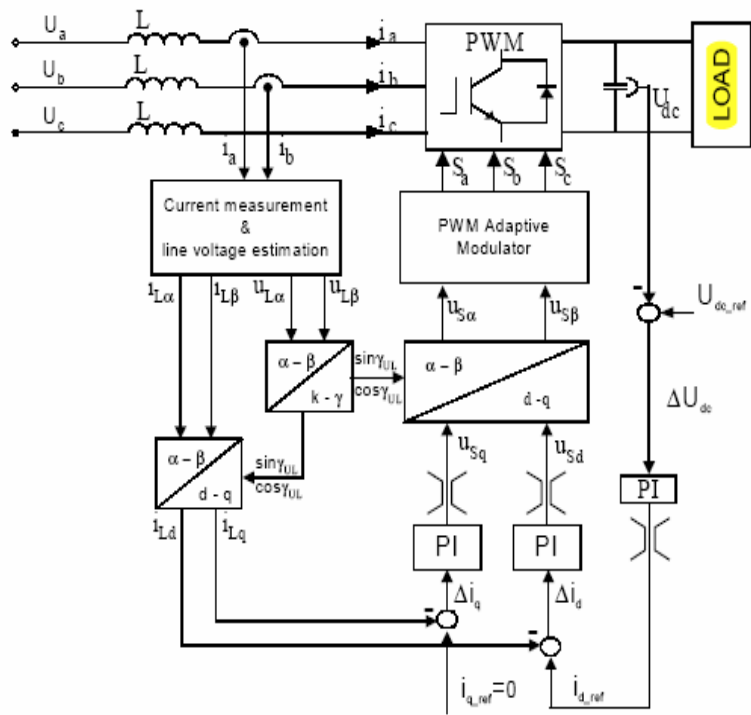

Fig.4. Voltage oriented method (VOC) control method Block scheme

Another voltage estimation based control strategy, is direct power control (DPC) that is based on the instantaneous active $\&$ reactive power control loops and no PWM modulator block. In this method the converter switching state are appropriately selected by a switching table based on the instantaneous errors between the command and estimated values of active and reactive power. Hence the key point for implementation of DPC strategies is a correct and fast estimation of the active and reactive line power [5]. Fig.5 shows the block diagram of the DPC method.

\section{Virtual Flux Estimation Based Methods}

The virtual flux based approach can be used to improve the VOC and DPC methods. In virtual flux estimation based method, the imposed line voltage in combination with $\mathrm{AC}$ side inductors are assumed as a virtual $\mathrm{AC}$ motor as shown in fig. $6[5,7]$. 


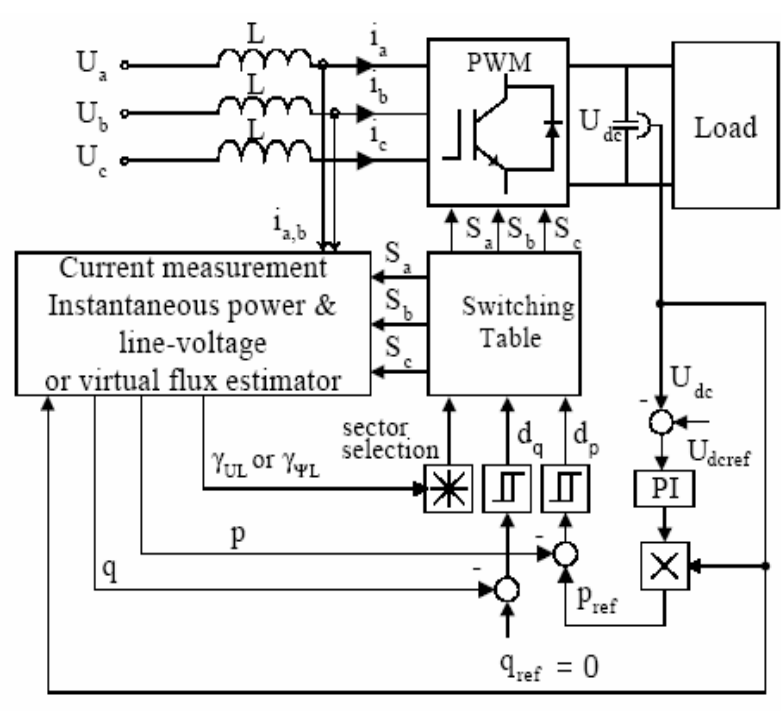

Fig.5. Direct power control method Block scheme

in this method the flux calculated from equations(6),(7):

$\underline{\varphi}_{L}=\int \underline{U}_{L} d t$

$\underline{\varphi}_{L}=\left[\begin{array}{c}\varphi_{L \alpha} \\ \varphi_{L \alpha}\end{array}\right]=\left[\begin{array}{l}\int U_{L \alpha} d t \\ \int U_{L \beta} d t\end{array}\right]$

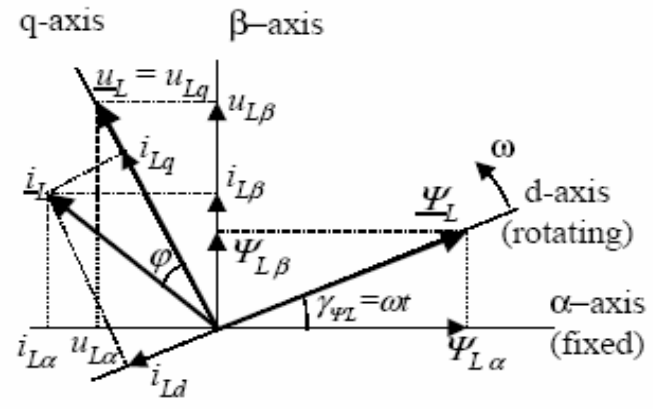

Fig.6. Vector diagram of voltage and current and flux in virtual flux

Fig .7 shows the improved VOC method based on virtual flux approach (VF-VOC). Two previous method (VOC and DPC) methods can be improved based on virtual flux method so that two new methods namely VF-VOC and VF-DPC could be obtained. The VF-VOC methods have a simple algorithm rather than previous VOC method and the fast dynamic response is obtained without internal current loop. Also using virtual based method in DPC control system permits its implementation with less sampling frequency. Moreover VF-DPC presents good performance in imbalance and harmonic conditions.

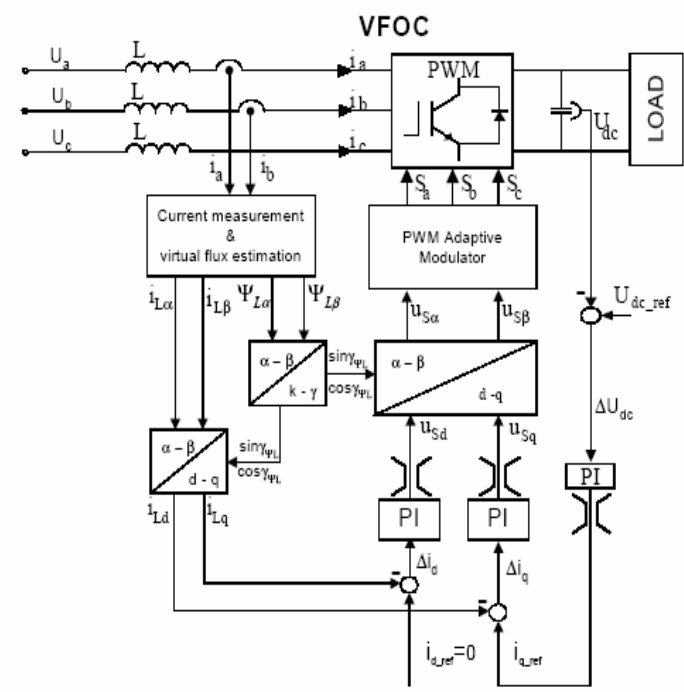

Fig.7. VF-VOC method Block scheme

\section{DPC Method Equations}

In this section the operation of the DPC method is discussed and simulated. Fig.8 shows the block diagram of the DPC system and motor drive $[5,7]$.

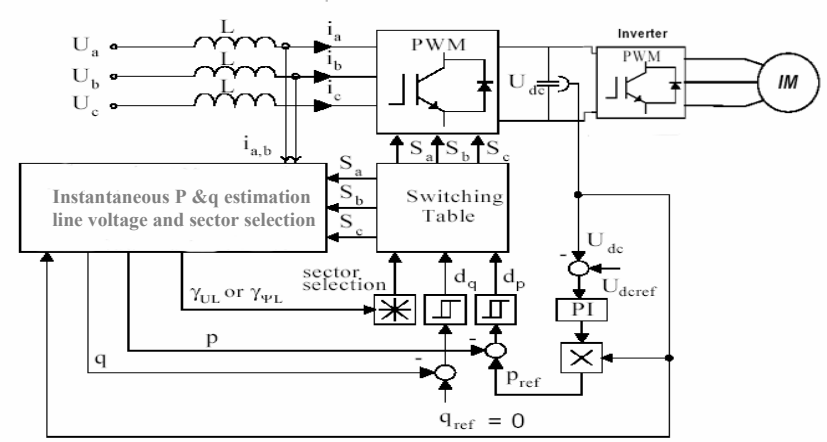

Fig.8. Block scheme of DPC

In this system the instantaneous active and reactive power are estimated by the equations8,9. In this equation $i_{a}, i_{b}, i_{c}$ are the ac-line measured current and the $s_{a}, s_{b}, s_{c}$ are the switching state of the converter. To compute $\mathrm{P} \& \mathrm{Q}$ value from equations 8,9 , require to know line inductance L [7].

$P=L\left(\frac{d i_{a}}{d t} i_{a}+\frac{d i_{b}}{d t} i_{b}+\frac{d i_{c}}{d t} i_{c}\right)+U_{d c}\left(S_{a} i_{a}+S_{a} i_{a}+S_{a} i_{a}\right)$

$q=\frac{1}{\sqrt{3}}\left(3 L\left(\frac{d i_{a}}{d t} i_{c}-\frac{d i_{c}}{d t} i_{a}\right)-U_{d c}\left[s_{a}\left(i_{b}-i_{c}\right)+s_{b}\left(i_{c}-i_{a}\right)+s_{a}\left(i_{a}-i_{b}\right)\right]\right)$

(9)

By measuring AC-line current and computing active and reactive power by eqs. 8,9 , the line voltage can easily be calculated from the equation 10 . 


$$
\left[\begin{array}{c}
u_{l \alpha} \\
u_{l \beta}
\end{array}\right]=\frac{1}{i_{l \alpha}+i_{l \beta}}\left[\begin{array}{cc}
i_{l \alpha} & -i_{l \beta} \\
i_{l \beta} & i_{l \alpha}
\end{array}\right]\left[\begin{array}{c}
p \\
q
\end{array}\right]
$$

Fig 9 shows the instantaneous active power, reactive power and ac voltage estimator block:

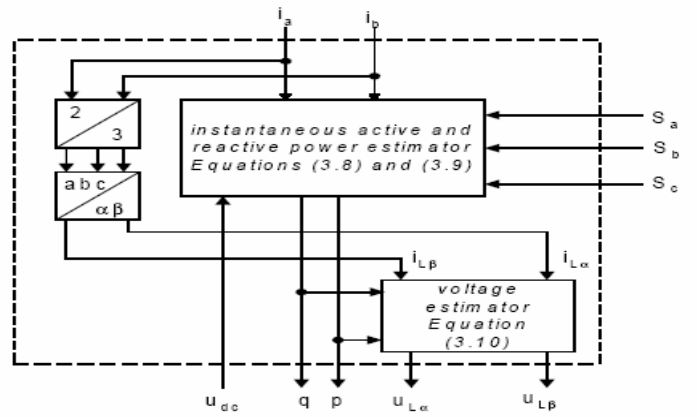

Fig.9. Instantaneous active and reactive power estimation

As in this system the active and reactive powers are estimated at each time (as shown in fig.9), the digitized output signal of the reactive and active power controller can be defined as:

$$
\begin{aligned}
& d_{q}=1 \text { for } q<q_{\text {ref }}-H_{q} \\
& d_{q}=0 \text { forq }>q_{\text {ref }}+H_{q}
\end{aligned}
$$

Where $\mathrm{H}_{\mathrm{q}}$ and $\mathrm{H}_{\mathrm{p}}$ are the hysteresis band. Table I shows

\begin{tabular}{|c|c|c|c|}
\hline$d_{p}$ & $d_{q}$ & Sector A & Sector B \\
\hline 0 & 1 & VB & V7 \\
\hline 0 & 0 & V0 & V0 \\
\hline 1 & 1 & VB & VB \\
\hline 1 & $\mathbf{0}$ & VA & VA \\
\hline \multicolumn{4}{|c|}{$\begin{array}{c}\mathrm{VA}=\mathrm{V1}(100), \mathrm{V} 2(110), \mathrm{V3}(010), \mathrm{V} 4(011), \mathrm{V} 5(001), \mathrm{V} 6(101 \\
\mathrm{VB}=\mathrm{V6}(101), \mathrm{V1}(100), \mathrm{V} 2(110), \mathrm{V3}(010), \mathrm{V} 4(011), \mathrm{V5}(001 \\
\mathrm{V} 0=\mathrm{V} 0(000), \mathrm{V} 7(111)\end{array}$} \\
\hline
\end{tabular}
the switching table for DPC control.

Table.1. Switching table for 12 sectors

Fig.10 shows the 12 sector voltage plane for switching table.

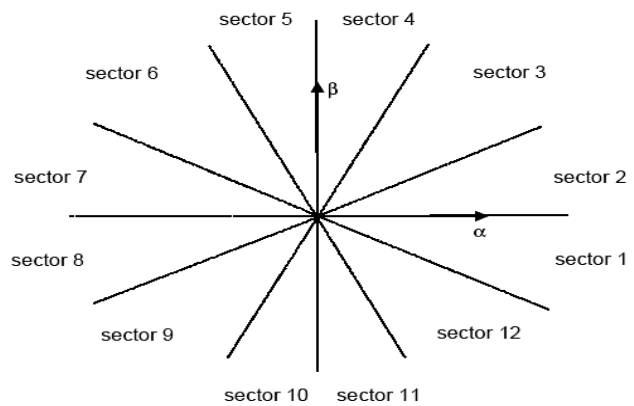

Fig.10. Voltage plane with 12 sectors

In this figure region of the voltage is divided in to twelve sectors, the area between adjoining vectors contain two sectors. Sector A is located closer to UA and sector B closer to UB.

\section{Simulation Results}

To study the operation of the voltage based DPC/PWM rectifier, it is implemented in SIMULINK/MATLAB environment. The simulation results obtained for different conditions and shown in fig. 11 to 22 . The de link voltage variation, when step change applied to $V d c_{\text {ref }}$ (from 380 to 480 volt) is shown in figure11. Fig. 12 shows the active and reactive power in ac line side when the step change is applied. To obtain a unity power factor in AC line side the input reference of reactive power is set to zero and active power changes, so the dc voltage is regulated at set point value. As shown in this figure the reactive power is approximately equal to zero $(\mathrm{pf}=1)$. The line current and voltage is shows in fig.13. As shown in this figure the line current is approximately sinusoidal and has the same phase respect to line voltage. The effect of dc side load on the operation of system is shown in figures 14 to 16 . As shown in these figures the change in load don't affect DC link voltage and only change the amplitude of the line current and the line side active power. The line current phase and reactive power will remain constant. Line voltage disturbance such as voltage sag and voltage unbalance are often considerable in industrial applications. For example, ANSI statistics in united state distribution system show that $\% 66$ of this system has less than $\% 1$ voltage unbalance, $\% 98$ of system has less than $\% 3$ voltage unbalance. To study the operation of DPC method in ac line voltage disturbed condition, simulation is performed for voltage unbalance and voltage sag in ac line side. The simulation result for voltage unbalance condition is shown in figures 17 to 19 . As shown in these figures, the control system regulates the DC link voltage in this disturbed voltage conditions as well as balance condition. In classical drive system a diode rectifier provide dc bus voltage. In this type of drives, a voltage sag in AC line side, cause a voltage deep on dc bus and led to a fault in drive operation. In PWM rectifier the control loop guaranties the dc-link voltage regulation in different conditions. Fig 20-22 shows the simulation results when symmetrical three phase voltage sag occur in AC line side. As shown in these figures in voltage sag duration the active and reactive power change but the DC bus voltage have remained constant, in voltage sag period and also after voltage sag is recovered.
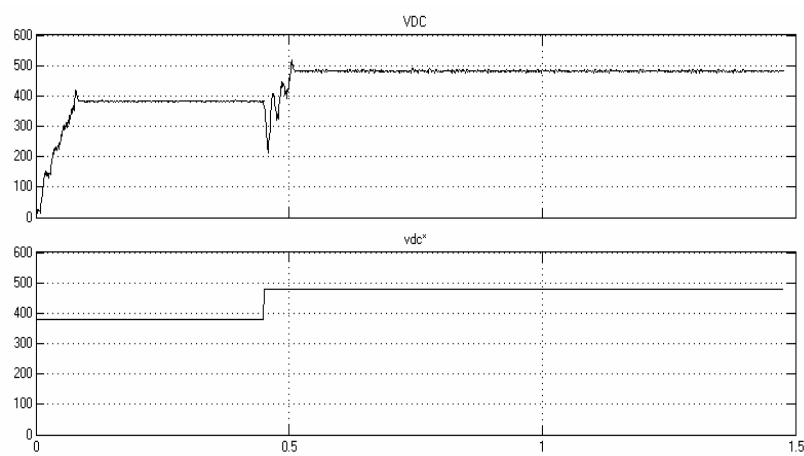

Fig.11. Control system step response ( $\mathrm{Vdc}^{*}=380$ to 480$)$ 

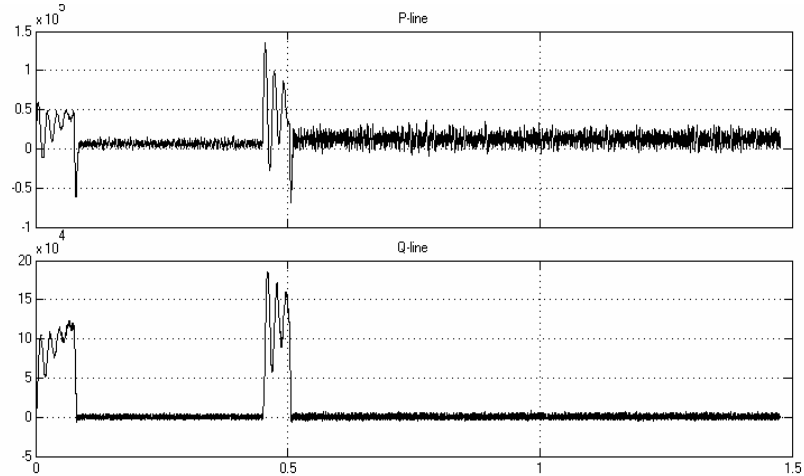

Fig.12. Active and reactive time variation after step change $(\mathrm{q}=0)$
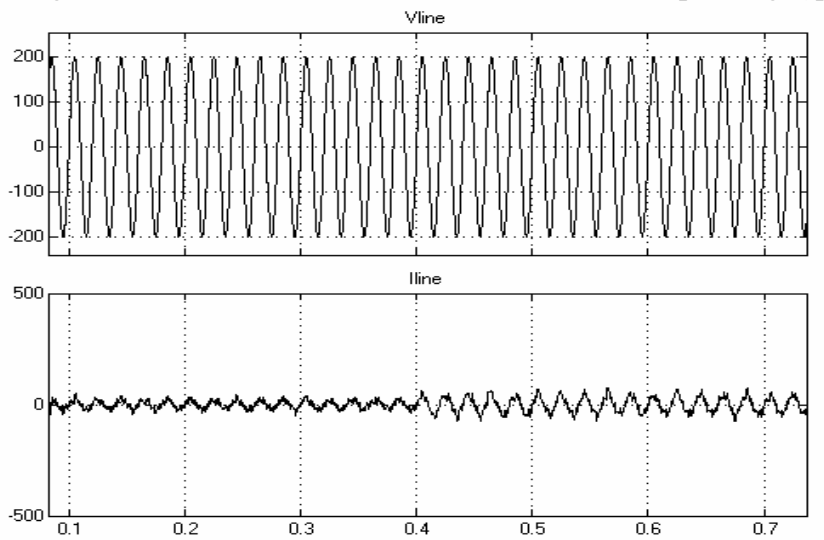

Fig.14. Line current variation after change in load
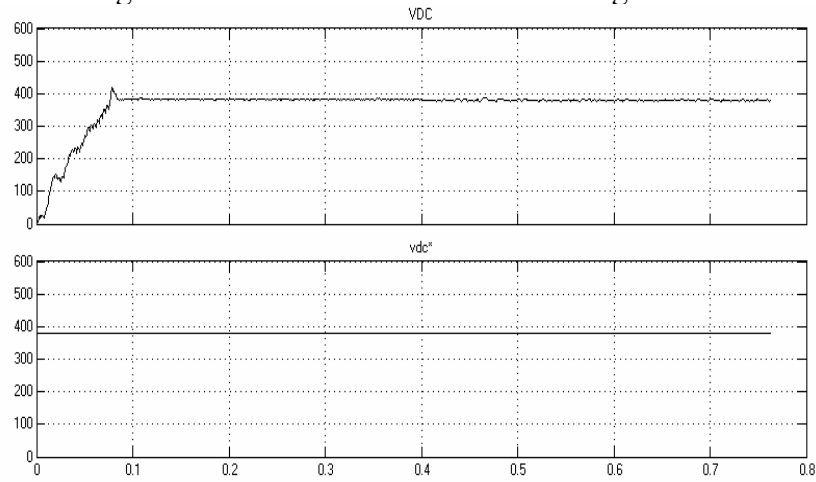

Fig.16. DC -link voltage variation with change in load
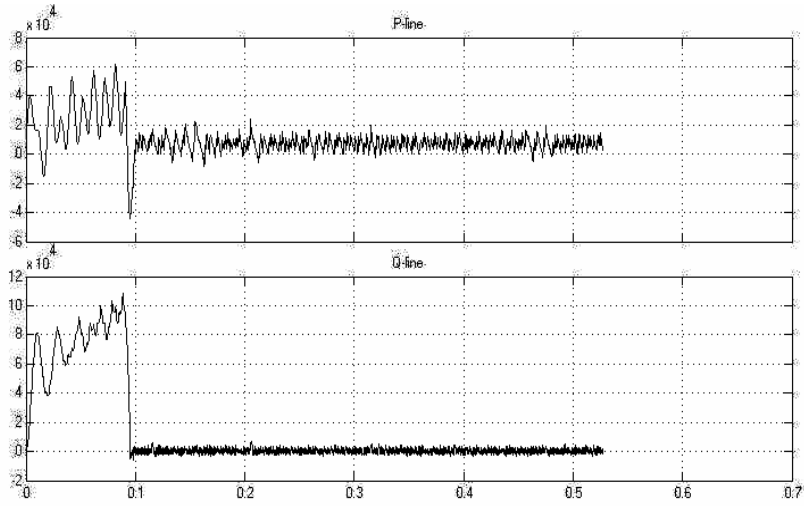

Fig.18. Change in active and reactive power in voltage unbalances condition
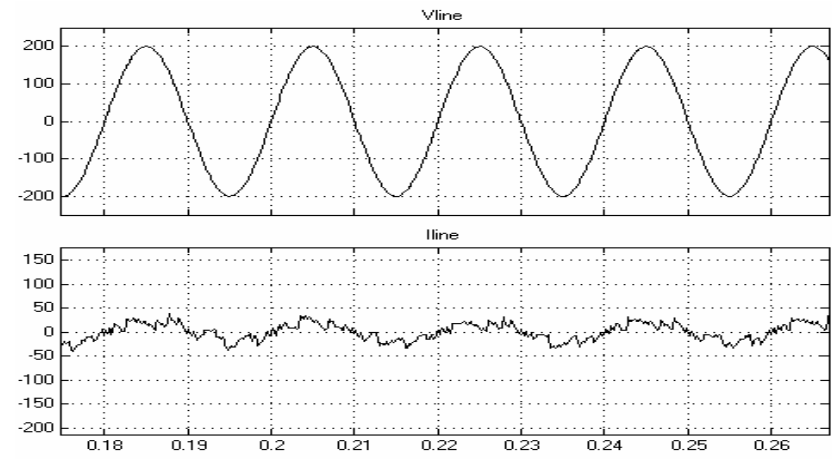

Fig.13. Input sinusoidal line current with respect to line voltage $(\mathrm{pf}=1)$
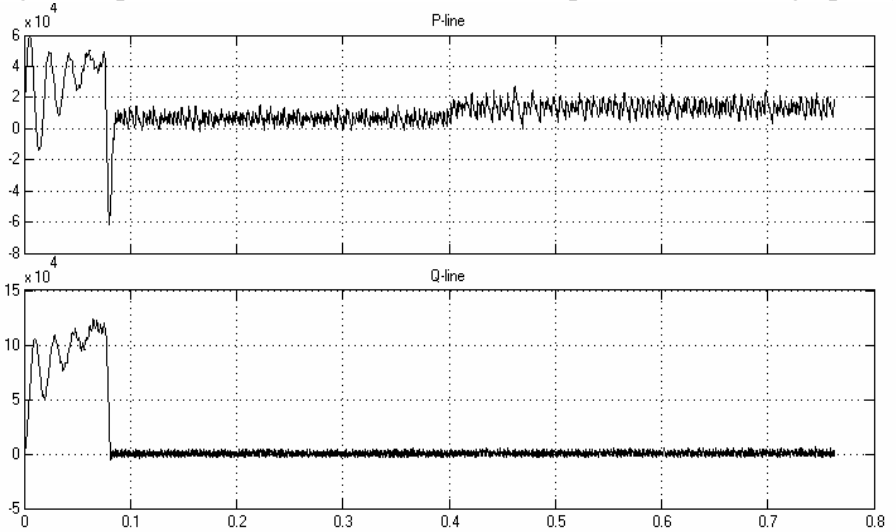

Fig.15. Variation in active and reactive power with change in load

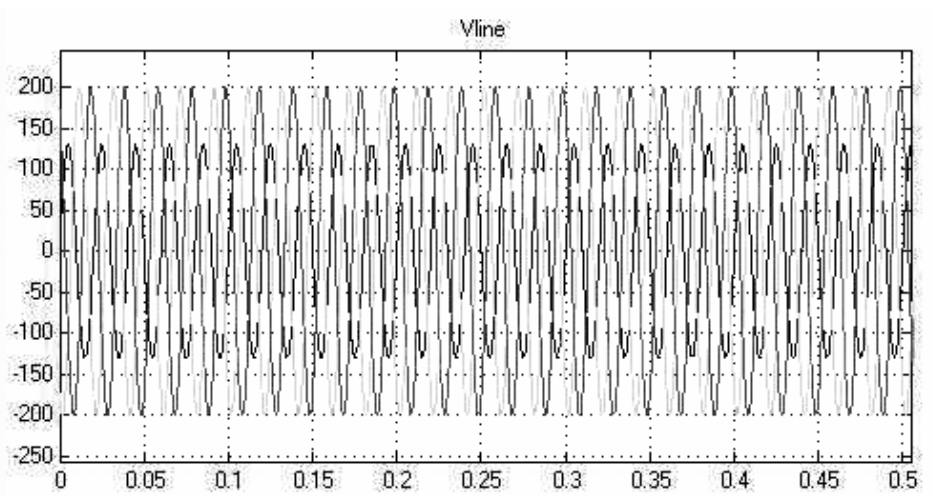

Fig. 17. Phase voltage waveform for $\% 35$ voltage unbalance
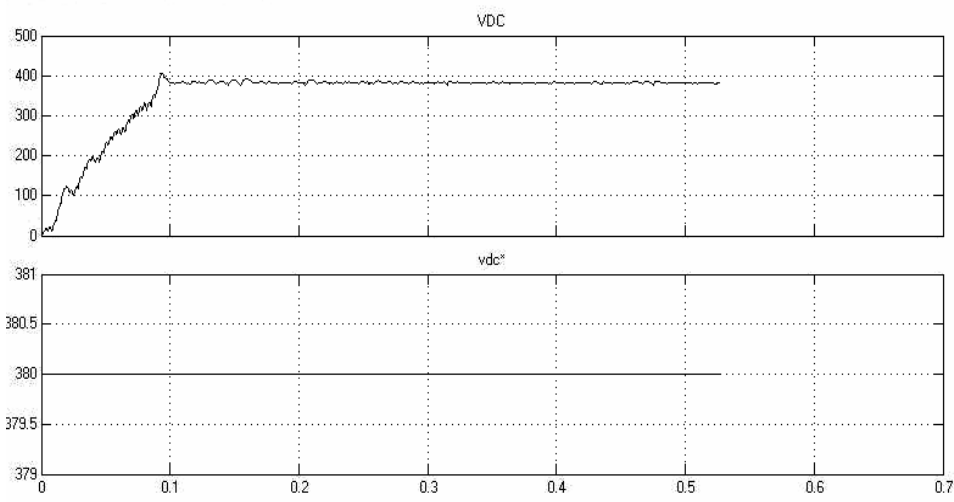

Fig. 19. Change in dc-link voltage in voltage unbalances condition 


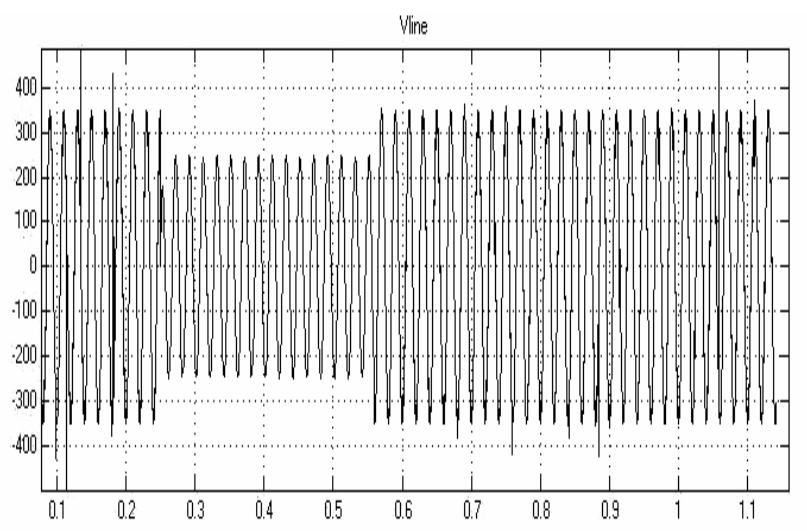

Fig.20. Line voltage wave form in voltage sag condition
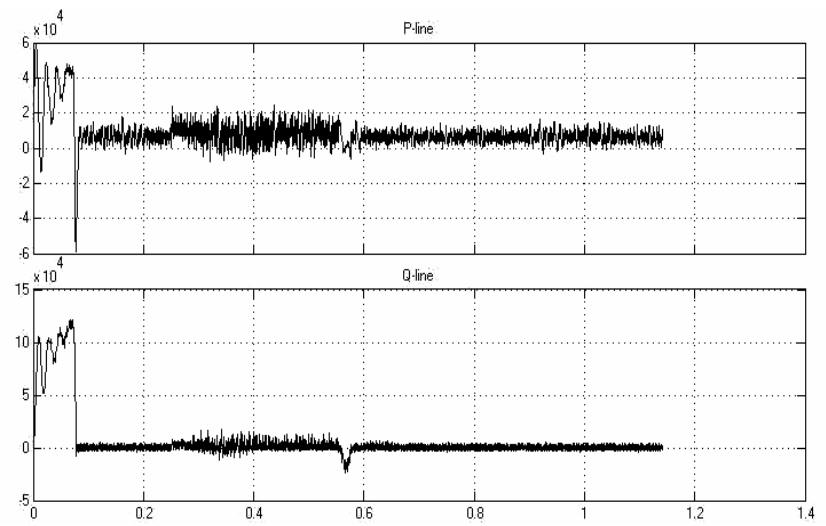

Fig.21.Change in active and reactive power in voltage sag Condition
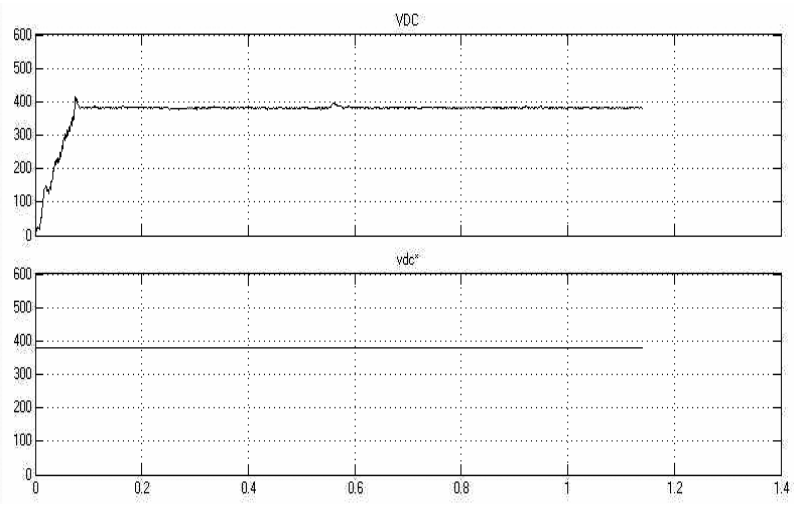

Fig.22.Change in dc-link voltage in voltage imbalance condition

\section{Conclusion}

Regarding the advantages of PWM rectifier, in this paper different control strategies of PWM rectifiers is discussed. Then the direct power control method (DPC) is presented and focused on. To predict behavior of DPC /PWM rectifier in different load and supply conditions, dynamic model is implemented in SIMULINK/MATLAB. Since the line voltage is usually disturbed in distribution system, the performance of rectifier is simulated in voltage unbalance and voltage sag condition. Simulation results show that DPC/PWM rectifier, not only keep regulated
DC-link voltage, but also improve power quality indexes. It is an important advantage of this converter particularly in speed control drive system that the operation of drive should be robust for line voltage disturbed conditions. As simulation results show, the reactive power is programmable in this system and can be set to obtain unity power factor. Also the line current have sinusoidal wave form and because of high switching frequency, THD is very low.

\section{References}

[1] Marian P.Kazmierkowski, "Control strategies for PWM rectifier/inverter-fed induction motors" ,IEEE conference, Volume: 1, Page(s): TU15 -TU23 vol.1, june2000

[2] D.Rendusara, P.Enjeti, "A method to reduce common mode \& different mode $\mathrm{dv} / \mathrm{dt}$ the motor terminals in PWM rectifier/PWM inverter Type adjustable speed drive systems", Applied Power Electronics Conference and Exposition, Volume: 2 , Page(s): 1010 -1016 vol.2 ,1998

[3]Xiong Jian,Kang Yong, Duan Shan Xu, Zhang Kai ,Chen Jian ,"simplified control circuit of three phase PWM rectifier"1999,IEEE

[4]G.D.Marques ;"A PWM rectifier control system with DC current control based on the space vector modulation and stabization" Power Electronics and Variable Speed Drives, 1998. Seventh International Conference on (Conf. Publ. No. 456) Published: 1998 , Page(s): 74 -79

[5]Mariusz Malinowski, Marian P.Kazmierkowski, andrzej Tryznadlowski;" Direct power control with virtual flux estimation for three-phase PWM rectifiers" Industrial Electronics, 2000. ISIE 2000. Proceedings of the 2000 IEEE International Symposium on Published: 2000 Volume: 2 , Page(s): 442 -447 vol.2

[6]Steffan Hansen,Mariusz Malinowski, Frede Blaabjerg, Marian P.Kazmierkowski "Sensorless Control Strategies for PWM rectifier", Applied Power Electronics Conference and Exposition, 2000. APEC 2000. Fifteenth Annual IEEE Published: Volume: 2 , Page(s): 832 -838 vol.2, 2000

[7] Mariusz Malinowski, Marian P.Kazmierkowski, Frede Blaabjerg "Virtual-flux based direct power control of three-phase PWM rectifier", IEEE, VOL.37,NO.4, july/august 2001

[8]Shimizu, T.; Fujita, T.; Kimura, G.; Hirose, J. ,A unity power factor PWM rectifier with DCripple compensation ,Industrial Electronics, IEEE Transactions on Published: Aug. 1997 VOlume: 444 , Page(s): 447 -455

[9]Woo-Cheol Lee; Taeg-Joon Kweon; Dong-Seok Hyun; Taeck-Kie Lee A novel control of three-phase PWM rectifier using single current sensor Power Electronics Specialists Conference. PESC 99. 30th Annual IEEE Published: 1999 Volume: 1, Page(s): 515 520 vol.1 , 1999

[10] Jian; Kang Yong; Duan Shan Xu; Zhang Kai; Chen Jian ,"Simplified control circuit of three phase PWM rectifier "Applied Power Electronics Conference and Exposition, 1999. APEC '99. Fourteenth Annual Published: 1999 Volume: 1, Page(s): 229 -233 vol. 